PEST MANAGEMENT

\title{
Redução da Sobrevivência da Broca-do-Café, Hypothenemus hampei (Ferrari) (Coleoptera: Scolytidae), e do seu Ataque aos Frutos de Café pela Pulverização com Nim em Laboratório
}

\author{
Rogério A Depieri ${ }^{1,2}$, Sueli S MARTINEZ ${ }^{1}$ \\ ${ }^{1}$ Área de Proteção de Plantas, Instituto Agronômico do Paraná, CP 481, 86001-970, Londrina, PR, Brasil; \\ radepieri@gmail.com, suemart@iapar.br, ${ }^{2 B}$ Bolsista CBP\&D/Café; endereço atual: Laboratório de Entomologia, \\ Embrapa Soja, CP 231, 86001-970, Londrina, PR, Brasil
}

Edited by André L Lourenção - IAC

Neotropical Entomology 39(4):632-637 (2010)

Reduced Survival and Infestation of Coffee Borer, Hypothenemus hampei (Ferrari) (Coleoptera: Scolytidae), on Coffee Fruits, in Response to Neem Sprays in Laboratory

\begin{abstract}
Aqueous solutions of neem oil and aqueous extracts of neem seeds and leaves were sprayed on coffee fruits for laboratory evaluation of their efficiency in reducing infestation of the coffee borer, Hypothenemus hampei (Ferrari), in multi-choice preference assays in laboratory. Neem oil and extracts reduced infestation of fruits in a dose-dependent manner, acting as a repellent. At $0.5 \%$, $1 \%$ and $1.5 \%$, the oil reduced fruit infestation by $30.2 \%, 42.5 \%(\mathrm{P}>0.05)$, and $58.6 \%(\mathrm{P} \leq 0.05)$, respectively, as compared with the control. Seed extracts at $1 \%, 2 \%$ and $4 \%(\mathrm{w} / \mathrm{v})$ reduced infestation by $30.9 \%, 38.3 \%(\mathrm{P}>0.05)$ and $70.2 \%(\mathrm{P} \leq 0.05)$, respectively; seed extracts at $0.15 \%, 1.5 \%$ and $15 \%(\mathrm{w} / \mathrm{v})$ reduced fruit infestation by $16.5 \%, 38.5 \%(\mathrm{P}>0.05)$ and $56.9 \%(\mathrm{P} \leq 0.05)$, respectively. Spraying the emulsifiable oil at $1 \%$ on coffee fruits and adult borers was compared with spraying on fruits or adults only. Adult-only spraying caused low mortality $(\mathrm{P}>0.05)$ and low reduction on the number of damaged fruits $(\mathrm{P}>0.05)$. Fruit-only spraying significantly reduced insect survival rates and the number of damaged fruits $(\mathrm{P} \leq 0.05)$. However, spraying on adults and fruits caused the greatest reduction in adult survival $(55.6 \% ; \mathrm{P} \leq 0.05)$ and in fruit infestation $(78.7 \% ; \mathrm{P} \leq 0.05)$, probably due to insect mortality and neem oil repellence acting together.
\end{abstract}

KEY WORDS: Botanical insecticide, Azadirachta indica, Meliaceae, repellence, Coffea arabica

A broca-do-café, Hypothenemus hampei (Ferrari), é uma praga economicamente importante encontrada na maioria dos países produtores de café (Murphy \& Moore 1990, Zevallos et al 1996, Souza \& Reis 1997). Pode infestar frutos verdes, maduros ou secos e causar sérios danos, como redução no peso e na qualidade dos frutos e mesmo da bebida.

A resistência da broca-do-café ao inseticida endosulfam (Brun et al 1989, 1994) e a preocupação com a saúde humana e o meio ambiente levaram à pesquisa sobre alternativas de controle, incluindo os extratos de plantas. $\mathrm{O}$ nim, Azadirachta indica (Meliaceae), tem sido amplamente estudado por seus compostos com ação inseticida e repelente [Saxena 1987, Schmutterer 1990, 1995, Mordue (Luntz) \& Nisbet 2000, Martinez 2002]. Dentre os muitos componentes ativos isolados dessa Meliaceae, como salanina, meliantrol, gedunina, nimbolina, nimbinem, dacetilsalanina, o tetranortriterpenoide azadiractina é o composto mais ativo biologicamente, e encontra-se no extrato ou óleo das sementes de nim. Embora a presença da azadiractina não tenha sido comprovada nas folhas, outros compostos terpenóides com propriedades semelhantes estão presentes (Schmutterer 1995)

A azadiractina apresenta principalmente efeito deterrente alimentar e regulador de crescimento [Mordue (Luntz) \& Nisbet 2000]. Também tem sido registrada sua ação em diversos processos fisiológicos (Schmutterer \& Ascher 1987, Correia et al 2009), redução da fecundidade e fertilidade, repelência e mortalidade (Schmutterer 1995).

Os efeitos do óleo e de extratos de nim em outra praga do cafeeiro, Leucoptera coffeella (Guérin-Méneville) (Lepidoptera: Lyonetiidae), foram demonstrados em laboratório por Martinez et al (2003), que obtiveram repelência de postura e redução da germinação dos ovos, ocasionando redução de $77 \%$ e $89 \%$ do número de lagartas eclodidas, quando se utilizaram soluções de óleo emulsionável de nim a $0,125 \%$ e $0,25 \%$, respectivamente.

Em estudos de controle da broca-do-café no campo, Sponagel (1994) observou que uma solução aquosa de óleo de nim a $2,5 \%$ enriquecida com azadiractina a $0,2 \%$ reduziu o número de frutos de café broqueados e causou mortalidade de adultos dentro dos frutos. Também, produtos à base de nim e extratos aquosos de sementes foram associados à redução 
de infestação de café no campo por Rodríguez-Lagunes et al (1998).

No presente estudo foram conduzidos testes de laboratório para avaliar a ação de extratos de nim e do óleo emulsionável à base de nim na sobrevivência de $H$. hampei e na infestação de frutos de café, buscando entender melhor a ação do nim observada no campo e seu potencial de utilização no controle da praga em cafeeiro.

\section{Material e Métodos}

As fêmeas de $H$. hampei utilizadas nos bioensaios foram obtidas em frutos de café coletados em área de produção orgânica de Coffea arabica em Londrina, PR. Os frutos contendo as brocas foram mantidos em laboratório (Hirose \& Neves 2002), em condições controladas $\left(25 \pm 3^{\circ} \mathrm{C}, 65\right.$ $\pm 15 \%$ UR e $12 \mathrm{~h}$ fotofase). Após três dias, os frutos foram peneirados em malha de $2 \mathrm{~mm}$ de diâmetro, sobre um tecido de poliéster branco e as fêmeas mais ativas de $H$. hampei foram coletadas com um aspirador bucal.

Os experimentos foram conduzidos em gaiolas de acrílico $(40 \times 30 \times 40 \mathrm{~cm})$ mantidas em condições controladas $(27 \pm$ $1^{\circ} \mathrm{C}, 65 \pm 10 \%$ UR, em ausência de luz).

\section{Preparo dos extratos}

Solução aquosa do óleo emulsionável à base de nim. A formulação comercial Dalneem ${ }^{\circledR}$ (azadiractina $0,1 \%$ ) foi diluída em água destilada para obter concentrações a 0,$5 ; 1$ e $5 \%$ de óleo.

Extrato aquoso de sementes. Frutos maduros de nim coletados no mês de abril em árvores plantadas no IAPAR Estação Experimental de Paranavaí, PR, foram despolpados em água corrente e as sementes secadas à sombra por cinco dias, e mantidas a $10^{\circ} \mathrm{C}$. As sementes foram trituradas em liquidificador com água destilada para preparar o extrato a 4\% (peso/volume - p/v). O triturado for mantido por aproximadamente $24 \mathrm{~h}$ à temperatura ambiente, no escuro, e então filtrado em um tecido de poliéster para remover os sólidos. $\mathrm{O}$ extrato das sementes foi diluído em água, para obter as concentrações $2 \%$ e $1 \%$ p/v.

Extrato aquoso de folhas. As folhas foram coletadas no mesmo período em árvores de nim plantadas no IAPAR Estação Experimental de Londrina. Em laboratório, elas foram lavadas em água corrente e imersas em uma solução a $1 \% \mathrm{NaClO}$ por $5 \mathrm{~min}$. Os folíolos foram removidos, lavados em água destilada e mantidos em câmara de fluxo laminar para secar por aproximadamente $4 \mathrm{~h}$. Em seguida, eles foram triturados em liquidificador com água destilada, para obter o extrato de folhas a $15 \% \mathrm{p} / \mathrm{v}$. O triturado foi mantido por aproximadamente $24 \mathrm{~h}$ à temperatura ambiente, no escuro, e então filtrado em tecido de poliéster fino. O extrato foi diluído em água, para obter as concentrações a $1,5 \%$ e $0,15 \% \mathrm{p} / \mathrm{v}$.

Avaliação do efeito repelente de nim sobre $\boldsymbol{H}$. hampei. Testes de livre escolha foram conduzidos em laboratório para avaliar a eficiência de repelência dos extratos de nim e do óleo emulsionável de nim a H. hampei. Os experimentos foram conduzidos em desenho experimental totalmente ao acaso, separadamente para cada extrato, nas seguintes concentrações: solução aquosa de óleo emulsionável, $0 ; 0,5$; $1 ; 1,5 \%$; extrato aquoso de sementes, $0 ; 1 ; 2 ; 4 \%$; extrato aquoso de folhas, $0 ; 0,15 ; 1,5 ; 15 \%$.

Frutos de café maduros foram coletados em plantas de $C$. arabica $\mathrm{cv}$. IAPAR 59 não-pulverizadas com inseticidas. Os pedúnculos dos frutos foram removidos e os frutos colocados em placas de Petri forradas com papel filtro.

Para cada tratamento, 30 frutos de café foram colocados em cinco placas de Petri forradas com papel filtro e pulverizados em torre de Potter $\left(8 \mathrm{ml}-4,5 \mathrm{lb} / \mathrm{pol}^{2}\right)$. Na testemunha, os frutos foram pulverizados com água destilada. Após a pulverização, os frutos foram secados à temperatura ambiente por $4 \mathrm{~h}$ e transferidos para placas de Petri limpas.

As placas, sem tampas, contendo os frutos foram colocadas dentro de cinco gaiolas de acrílico $(40$ × 50 × 50 $\mathrm{cm}$ ), sendo que uma placa de cada concentração foi colocada em cada gaiola, a qual consistia em uma repetição. Em seguida, 200 fêmeas adultas foram liberadas no centro de cada gaiola. Cinco dias após a pulverização, os números de frutos broqueados e não-broqueados foram registrados. Os dados foram submetidos ao teste não-paramétrico de comparação de médias de Kruskal-Wallis ( $\mathrm{P} \leq 0,05)$, utilizando o Programa SAS (SAS Institute 1999-2001).

Avaliação da ação letal do óleo emulsionável de nim sobre H. hampei e da associação da mortalidade à repelência na redução do número de frutos broqueados. Dois testes independentes de não preferência foram conduzidos, seguindo desenho experimental totalmente ao acaso. Os frutos de café e os insetos usados nestes ensaios tiveram a mesma origem daqueles utilizados no ensaio anterior; a pulverização foi realizada em torre de Potter, com o mesmo volume e pressão.

No primeiro experimento, avaliou-se o efeito da pulverização da solução aquosa do óleo emulsionável de nim a $1 \%$, sobre os frutos de café e também sobre $H$. hampei, comparando com a pulverização apenas nos frutos e apenas nos insetos, separadamente. $\mathrm{O}$ experimento compreendeu quatro tratamentos: 1) fêmeas pulverizadas com o óleo e frutos pulverizados somente com água destilada; 2) frutos pulverizados com o óleo e fêmeas pulverizadas somente com água destilada; 3) brocas e frutos pulverizados com o óleo e 4) testemunha: fêmeas e frutos e pulverizados com água destilada.

Para cada tratamento quatro placas de Petri forradas com papel filtro contendo 20 frutos cada foram pulverizadas com óleo de nim ou água destilada. Depois de secos, os frutos foram transferidos para placas de Petri limpas. Quatro placas de cada tratamento foram colocadas por gaiola de acrílico, distribuídas de forma equidistante. Três repetições (gaiolas) foram utilizadas por tratamento. Em cada gaiola, foram liberadas 100 fêmeas previamente pulverizadas. Após cinco dias, os insetos vivos e os mortos foram contados, assim como os frutos broqueados e não broqueados. Os dados foram submetidos ao teste não-paramétrico de comparação de médias de Kruskal-Wallis ( $\mathrm{P} \leq 0,05)$, utilizando o Programa SAS (SAS Institute 1999-2001).

No segundo experimento, avaliou-se novamente a mortalidade de brocas e o número de frutos broqueados, 
pulverizando-se, nas mesmas condições do experimento anterior, ambos os frutos e as fêmeas de H. hampei com solução aquosa do óleo emulsionável de nim a $1 \%$, em comparação com insetos e frutos não tratados, também em teste sem chance de escolha. Quatro placas do mesmo tratamento, cada uma com 30 frutos, foram colocadas por gaiola de acrílico, a qual consistia em uma repetição. Foram utilizadas três repetições para cada tratamento. Em seguida, 150 brocas fêmeas previamente submetidas ao mesmo tratamento que os frutos foram liberadas no centro de cada gaiola. Cinco dias após a pulverização, os insetos vivos e mortos foram contados, assim como o número de frutos broqueados e não-broqueados. Os dados foram analisados pelo teste não paramétrico de Wilcoxon para duas médias $(\mathrm{P} \leq 0,05)$, utilizando o Programa SAS (SAS Institute 19992001).

\section{Resultados e Discussão}

Avaliação do efeito repelente do nim sobre $H$. hampei. A pulverização de óleo emulsionável de nim sobre os frutos de café reduziu o número de frutos broqueados de modo dependente da dose (Tabela 1). As brocas preferiram os frutos não tratados sendo que $70,7 \%$ destes se encontravam infestados após cinco dias. Apesar de as concentrações de $1 \%$ e $0,5 \%$ de óleo de nim terem reduzido a porcentagem de frutos broqueados em $42,4 \%$ e $30,3 \%$, respectivamente em comparação com o controle, a diferença foi significativa apenas na maior concentração, 1,5\% (azadiractina $=15 \mathrm{mg} / \mathrm{l})$ $\left(\mathrm{DF}=3 ; \chi^{2}=14,0913 ; \mathrm{P} \leq 0,05\right)$, que reduziu o número de frutos broqueados em $58,6 \%$ em comparação com o tratamento controle. Nas concentrações mais altas, além de o número de frutos broqueados ter sido menor, muitos dos frutos apresentavam apenas arranhaduras leves.

Esses resultados corroboram os obtidos no México por Rodríguez-Lagunes et al (1998), que observaram que uma emulsão aquosa a $0,2 \%$ de uma formulação comercial de óleo emulsionável de nim (azadiractina $=8 \mathrm{mg} / \mathrm{l}$ ) reduziu o número de frutos infestados com a broca-do-café no campo em 58\%. No Equador, Sponagel (1994) realizou três pulverizações de solução aquosa de óleo de nim a 2,5\% (azadiractina $=4 \mathrm{mg} / \mathrm{l}$ ) sobre café, no campo, e não observou redução no número de frutos infestados. Entretanto, quando mais azadiractina foi adicionada ao óleo de nim, alcançando $20 \mathrm{mg} / \mathrm{l}$, a emulsão apresentou ação repelente, e até $80 \%$ dos frutos foram apenas levemente arranhados. As variações na redução do número de frutos broqueados em relação às concentrações utilizadas nos diversos trabalhos podem estar relacionadas à ausência de padronização no preparo dos extratos e dos produtos comerciais disponíveis e também por sua natureza biológica. Além disso, segundo Damarla (2001), a azadiractina é instável em altas temperaturas, em presença de luz e umidade, o que pode ocasionar variações em seu teor, dependendo de como as sementes de onde se extrai o óleo são colhidas e armazenadas.

Tabela 1 Frutos de café broqueados por Hypothenemus hampei cinco dias após pulverização com diferentes concentrações de soluções aquosas de óleo emulsionável de nim, e extratos aquosos de semente e de folhas de nim $\left(27 \pm 1^{\circ} \mathrm{C}, \mathrm{UR} 65 \pm\right.$ $5 \%$, em ausência de luz).

\begin{tabular}{|c|c|c|}
\hline Tratamento & $\begin{array}{l}\text { Frutos broqueados }(\%) \\
\qquad(\mathrm{n}=30)\end{array}$ & $\begin{array}{l}\text { Redução do ataque em } \\
\text { relação à testemunha (\%) }\end{array}$ \\
\hline \multicolumn{3}{|c|}{ Óleo emulsionável de nim (\%) } \\
\hline 0 & $70,7 \pm 1,25 \mathrm{a}$ & - \\
\hline 0,5 & $49,3 \pm 4,27 \mathrm{ab}$ & 30,3 \\
\hline 1 & $40,7 \pm 2,21 \mathrm{ab}$ & 42,4 \\
\hline 1,5 & $29,3 \pm 7,18 b$ & 58,6 \\
\hline \multicolumn{3}{|c|}{ Extrato aquoso de sementes (\%) } \\
\hline 0 & $62,7 \pm 2,45 \mathrm{a}$ & - \\
\hline 1 & $43,3 \pm 8,50 \mathrm{ab}$ & 30,9 \\
\hline 2 & $38,7 \pm 9,10 \mathrm{ab}$ & 38,3 \\
\hline 4 & $18,7 \pm 4,90 \mathrm{~b}$ & 70,2 \\
\hline \multicolumn{3}{|c|}{ Extrato aquoso de folhas (\%) } \\
\hline 0 & $72,7 \pm 6,94 \mathrm{a}$ & - \\
\hline 0,15 & $60,7 \pm 5,52 \mathrm{a}$ & 16,5 \\
\hline 1,5 & $44,7 \pm 8,53 \mathrm{ab}$ & 38,5 \\
\hline 15 & $31,3 \pm 4,55 b$ & 56,9 \\
\hline
\end{tabular}

Médias seguidas pela mesma letra nas colunas, para cada experimento, não são significativamente diferentes pelo teste nãoparamétrico de comparações de médias de Kruskal-Wallis $(\mathrm{P}>0,05)$. 
A proteção dos frutos pela pulverização de formulações Comerciais de nim tem sido relatada para outros coleópteros, como o bicudo-do-algodoeiro, Anthonomus grandis Boheman (Coleoptera: Curculionidae); o produto protegeu os frutos de algodão de infestações em laboratório (Showler et al 2004). Entretanto, no campo, esse efeito cessou três dias após o tratamento. Thacker et al (2003) encontraram que um produto comercial contendo óleo emulsionável de nim diluído em óleo vegetal protegeu sementes de coníferas contra infestação do curculionídeo Hylobius abietis L. por mais de dois meses no campo.

O extrato aquoso de sementes também reduziu o número de frutos infestados pela broca-do-café, de modo dependente da dose (Tabela 1). À concentração de $4 \%(\mathrm{p} / \mathrm{v})$, o extrato repeliu os adultos da broca, reduzindo o número de frutos broqueados em 70,2\% em comparação com o controle, no qual $62,7 \%$ dos frutos foram danificados $\left(\mathrm{DF}=3 ; \chi^{2}=9,9790\right.$; $\mathrm{P} \leq 0,05)$. Do mesmo modo que no experimento com o óleo, embora o número de frutos infestados nas concentrações $2 \%$ $(\mathrm{p} / \mathrm{v})$ e $1 \%(\mathrm{p} / \mathrm{v})$ tenha sido inferior ao tratamento controle, essas diferenças não foram significativas. A pulverização do extrato a essas concentrações reduziu o número de frutos broqueados em $38,3 \%$ e $30,9 \%$, respectivamente, em comparação com o tratamento controle.

A repelência foi mais baixa nos frutos pulverizados com extrato aquoso de folhas, e também dependente da dose. A $15 \%$, o número de frutos broqueados foi $56,9 \%$ mais baixo do que no controle, no qual as brocas perfuraram $72,7 \%$ dos frutos $\left(\mathrm{DF}=3 ; \chi^{2}=11,3454 ; \mathrm{P} \leq 0,05\right)$. Entretanto, o extrato a $1,5 \%$ reduziu o número de frutos infestados em $38,5 \% \mathrm{em}$ comparação com o controle, o que não foi muito diferente dos resultados obtidos com o óleo emulsionável e o extrato aquoso de sementes (Tabela 1).

A comparação dos resultados dos diferentes experimentos indica que o óleo emulsionável pode ser mais eficaz na proteção dos frutos de café do que os extratos de sementes e folhas. Utilizando-se o óleo emulsionável a $1 \%$, a redução no número de frutos broqueados foi de $42,4 \%$ em comparação com o controle, valor mais alto que o obtido com o extrato aquoso de sementes à mesma concentração $(30,9 \%)$ (Tabela 1). A $0,5 \%$, o óleo emulsionável ocasionou redução da quantidade de frutos broqueados semelhante à do extrato aquoso de sementes a $1 \%$, respectivamente, $30,3 \%$ e $30,9 \%$ em comparação ao controle. O óleo de nim foi também mais eficiente em proteger os frutos de café do que o extrato aquoso de folhas. A 1,5\%, o óleo de nim e o extrato de folhas reduziram a quantidade de frutos broqueados em $58,6 \% \mathrm{e}$ $38,5 \%$, respectivamente, em relação ao controle.

Nos três experimentos, a broca preferiu os frutos não tratados com extratos de nim, e o efeito de repelência à perfuração variou de acordo com a concentração. Às concentrações mais altas, o número de frutos broqueados foi menor e alguns frutos estavam apenas levemente arranhados superficialmente, indicando início de atividade de perfuração. A azadiractina reduz a alimentação de diversos grupos de insetos (Schoonhoven 1982, Martinez \& van Emden 1999, Mordue (Luntz) \& Nisbet 2000). Além disso, os quimiorreceptores da boca e dos tarsos dos insetos respondem negativamente a aleloquímicos como a azadiractina, e podem causar repelência pelo contato (Blaney \& Simmonds 1990). Ambos os mecanismos podem estar agindo em conjunto, explicando o número menor de frutos tratados perfurados e penetrados pela broca-do-café.

Ação letal do óleo emulsionável de nim sobre $H$. hampei e associação da mortalidade à repelência na redução do número de frutos broqueados. A pulverização de óleo de nim apenas sobre as fêmeas causou baixa mortalidade, $9 \%$ superior à testemunha $(\mathrm{P}>0,05)$, e reduziu pouco o número de frutos infestados, $14,2 \%$ inferior à testemunha $(\mathrm{P}>$ 0,05 ) (Tabela 2). Esse pequeno acréscimo na mortalidade das fêmeas pela pulverização do óleo de nim sobre inseto reforça a baixa ação de contato do óleo de nim, como anteriormente observado para outras espécies (Vinuela et al 1998, Santolamazza-Carbone \& Fernández-de-AnaMagán 2004, Silva \& Martinez 2004). É provável que a baixa mortalidade observada para esses adultos, incluindo a broca-do-café, resulte da baixa capacidade de penetração dos extratos de nim através do tegumento dessess insetos, assim como demonstrado para Schistocerca gregaria (Forskal) (Orthoptera: Acrididae) (Nicol 1994).

Por outro lado, redução significativa na mortalidade da broca foi obtida quando somente os frutos foram pulverizados $(\mathrm{P} \leq 0,05)$ (Tabela 2). A mortalidade foi em média 58,0\% e pode ter sido causada principalmente pela ingestão do óleo de nim durante a perfuração do fruto. Carvalho (1996) comparou a ação de azadiractina por ingestão e aplicação tópica em lagartas de Spodoptera littoralis (Boisd.) (Lepidoptera: Noctuidae) e observou que 1 ppm de azadiractina por ingestão causou $100 \%$ de mortalidade, enquanto que a pulverização

Tabela 2 Mortalidade de fêmeas e número de frutos de café broqueados por Hypothenemus hampei cinco dias após sua pulverização com solução aquosa de óleo emulsionável de nim a $1 \%$, em diferentes tratamentos $\left(27 \pm 1^{\circ} \mathrm{C}\right.$, UR $65 \pm 5 \%$, em ausência de luz).

\begin{tabular}{lcc}
\hline Tratamento & Mortalidade de fêmeas $(\%)(\mathrm{n}=100)$ & Frutos broqueados $(\%)(\mathrm{n}=20)$ \\
\hline Testemunha & $32,7 \pm 3,00 \mathrm{a}$ & $64,6 \pm 2,60 \mathrm{a}$ \\
Fêmeas pulverizadas & $41,7 \pm 6,40 \mathrm{a}$ & $50,4 \pm 7,10 \mathrm{ab}$ \\
Frutos pulverizados & $58,0 \pm 6,00 \mathrm{~b}$ & $31,3 \pm 2,50 \mathrm{bc}$ \\
Fêmeas e frutos pulverizados & $88,3 \pm 1,50 \mathrm{c}$ & $13,8 \pm 1,25 \mathrm{c}$ \\
\hline
\end{tabular}

Médias seguidas pela mesma letra nas colunas não são significativamente diferentes pelo teste não paramétrico de comparações de médias de Kruskal-Wallis $(\mathrm{P}>0,05)$. 
Tabela 3 Número de frutos de café broqueados por Hypothenemus hampei e de fêmeas mortas, cinco dias após a pulverização de ambos com solução aquosa de óleo emulsionável de nim $\left(27 \pm 1^{\circ} \mathrm{C}\right.$, UR $65 \pm 5 \%$, escuro).

\begin{tabular}{ccc}
\hline Óleo emulsionável de nim (\%) & Mortalidade de fêmeas $(\%)(\mathrm{n}=150)$ & Frutos broqueados $(\%)(\mathrm{n}=30)$ \\
\hline 0 & $36,5 \pm 1,93 \mathrm{~b}$ & $63,1 \pm 2,00 \mathrm{a}$ \\
1 & $96,5 \pm 3,70 \mathrm{a}$ & $12,5 \pm 1,92 \mathrm{~b}$ \\
\hline
\end{tabular}

Médias seguidas pela mesma letra nas colunas não são significativamente diferentes pelo teste não-paramétrico de Wilcoxon $(\mathrm{P}>0,05)$.

de azadiractina a 100 ppm não causou mortalidade das lagartas.

Em consequência à mortalidade das brocas, o número de frutos broqueados decresceu, atingindo $31,3 \%(\mathrm{P} \leq 0,05)$. Esse resultado é importante para se programar a utilização do óleo de nim para controle da praga no campo, pois indica a possibilidade de a pulverização de ramos e frutos do cafeeiro reduzir o dano aos frutos, mesmo que ela não atinja a brocado-café. Entretanto, o tratamento com pulverização nos frutos e também nas fêmeas resultou em mortalidade mais elevada, 88,3\% (P $\leq 0,05)$, demonstrando a ação de contato nos insetos, associada à provável ação por ingestão durante a perfuração dos frutos tratados. Da mesma maneira, o número de frutos broqueados se reduziu significativamente para $13,8 \%$, indicando que a proteção do fruto pela pulverização dos insetos, mesmo que pequena, pode ser significativa. Esses resultados são comprovados no segundo experimento (Tabela 3 ), onde se pulverizaram as fêmeas e os frutos de café com óleo emulsionável a $1 \%$ e se obteve $96,5 \%$ de mortalidade das fêmeas, em comparação com a testemunha, $36,5 \%$ (DF $\left.=1 ; \chi^{2}=3,9706 ; \mathrm{P} \leq 0,05\right)$, e $12,5 \%$ de frutos broqueados, com $63,1 \%$ na testemunha $\left(\mathrm{DF}=1 ; \chi^{2}=3,8571 ; \mathrm{P} \leq 0,05\right)$ (Tabela 3).

Assim, as reduções no número de frutos de cafeeiro infestados pela broca-do-café no campo relatada por Rodrigues-Lagunes et al (1998) podem ter resultado da ação dos extratos de nim na mortalidade da broca-do-café associada com repelência, prejudicando a capacidade de colonização das fêmeas.

Os resultados obtidos no presente estudo sugerem que a pulverização do óleo emulsionável de nim e de extratos de folhas e sementes de nim pode levar os insetos à morte por contato e também pela ingestão da parte externa dos frutos contaminados, bem como pode causar repelência, resultando em níveis mais baixos de penetração pela broca nos frutos de café. Além disso, pulverizações do óleo de nim podem causar mortalidade da broca-do-café dentro do fruto, reduzindo futuras infestações, como demonstrado por Sponagel (1994), que obteve $26 \%$ de mortalidade da broca-do-café dentro de frutos, após pulverizar emulsão aquosa de óleo de nim contendo $10 \mathrm{mg} / \mathrm{l}$ de azadiractina, três vezes em condições de campo. O mesmo tratamento com óleo de nim enriquecido com $50 \mathrm{mg} / \mathrm{l}$ de azadiractina causou aproximadamente $65 \%$ de mortalidade de adultos dentro dos frutos. Esses resultados, portanto, demonstram o potencial dos diferentes produtos a base de nim na redução das infestações de broca em plantios de café. Entretanto, estudos de campo e determinação mais acurada de doses são necessários antes que se possa recomendar sua utilização para o controle dessa praga.

\section{Agradecimentos}

Os autores agradecem à Dra. Marinéia L Haddad, Esalq/ USP, e à Eng. Agr. MSc Maria Elizabeth C Vasconcelos, IAPAR, pela análise estatística e ao Consórcio Brasileiro de Pesquisa e Desenvolvimento do Café pelo suporte financeiro à pesquisa e bolsa ao primeiro autor.

\section{Referências}

Blaney W M, Simmonds M S J (1990) A behavioural and electrophysiological study of the role of tarsal chemoreceptors in feeding by adults of Spodoptera littoralis, Heliothis virescens and Helicoverpa armigera. J Insect Physiol 36: 743-756.

Brun L O, Marcillaud C, Gaudichon V (1994) Cross resistance between insecticides in coffee berry borer, Hypothenemus hampei (Coleoptera: Scolytidae), from New Caledonia. Bull Entomol Res 84: 175-178.

Brun L O, Marcillaud C, Gaudichon V, Scukling D (1989) Endosulfan resistance in Hypothenemus hampei (Coleoptera: Scolytidae) in New Caledonia. J Econ Entomol 82: 1311-1316.

Carvalho S M (1996) Effect of sublethal concentrations of azadirachtin on the development of Spodoptera littoralis. $\mathrm{PhD}$ thesis, University of Reading, Reading, 249p.

Correia A A, Wanderley-Teixeira V, Teixeira A A C, Oliveira J V de, Torres J B (2009) Morfologia do canal alimentar de lagartas de Spodoptera frugiperda (J E Smith) larvae (Lepidoptera: Noctuidae) alimentadas com folhas tratadas com nim. Neotrop Entomol 38: 83-91.

Damarla, S R (2001) Stability of azadirachtin - a review. In Kelany I M, Reinhard W (eds) Proceedings of the Workshop on Practice Oriented Results on Use of Plant Extracts and Pheromones. Cairo, p.11-12.

Hirose E, Neves P M O J (2002) Técnica para criação e manutenção da broca-do-café, Hypothenemus hampei (Ferrari) (Coleoptera: Scolytidae), em laboratório. Neotrop Entomol 31: 161-164.

Martinez S S (ed) (2002) O nim - Azadirachta indica - natureza, usos múltiplos, produção. IAPAR, Londrina, 142p.

Martinez S S, Meneguim A M (2003) Redução da oviposição e da sobrevivência de ovos de Leucoptera coffeella causadas pelo óleo emulsionável de nim. Man Integr Plagas 67: 30-34.

Martinez S S, van Emden H (1999) Sublethal concentrations of azadirachtin affected food intake, conversion efficiency 
and feeding behaviour of Spodoptera littoralis (Lepidoptera: Noctuidae). Bull Entomol Res 89: 65-71.

Mordue (Luntz) A J, Nisbet A J (2000) Azadirachtin from the neem tree Azadirachta indica: Its actions against insects. An Soc Entomol Brasil 29: 615-632.

Murphy S T, Moore D (1990) Biological control of the coffee berry borer Hypothenemus hampei (Ferrari) (Coleoptera: Scolytidae), previous programmer and possibilities for the future. Biocontr News Inf 11: 107-117.

Nicol C M Y (1994) Weitere untersuchungen zur kontaktwirtung des Samenöls des Niembaumes Azadirachta indica (A. Juss) bei gregären larven der wüstenheuschrecke Schistocerca gregaria (Forsk.). Mitt Deutschen Gesell Algem Angew Entomol 8: 791-793.

Rodrígues-Lagunes D A, Lagunes-Tejeda A, Riestro-Diaz D, Rodríguez-Maciel C, Velásquez-Mendoza J, Becerril-Roman E, Pacheco-Velasco E (1998) Extractos acuosos de nim para el combate de la broca de café. Man Integr Plagas 49: 73-77.

Santolamazza-Carbone S S, Fernandez-de-Ana-Magan F A (2004) Testing of selected insecticides to assess the viability of the integrated pest management of the Eucalyptus snout-beetle Gonipterus scutellatus in north-west Spain. J Appl Entomol 128: 620-627.

SAS Institute (1999-2001) SAS/STAT user's guide, version 8.02. SAS Institute Inc., Cary, NC.

Saxena R C (1987) Neem seed derivatives for management of rice insect pest - a review of recent studies, p.93-98. In Schmutterer H, Ascher K R S (eds) Natural pesticides from the neem tree and other tropical plansts. Proceedings of the Third International Neem Conference. Nairob, GTZ, Eschborn, 1987, 703p.

Schmutterer H (1990) Properties and potential of natural pesticides from the neem tree, Azadirachta indica. Annu Rev Entomol 35: 271-297.

Schmutterer H (ed) (1995) The neem tree Azadirachta indica A. Juss. and other meliaceous plants. VCH, Weinheim, 696p.

Schmutterer H, Ascher K R S (eds) (1987) Natural pesticides from the neem tree and other tropical plants. Proceedings of the $3 \mathrm{rd}$
International Neem Conference, 1986, Nairobi, Quênia, GTZ, Eschborn, 703p.

Schoonhoven L M (1982) Biological aspects of antifeedants. Entomol Exp Appl 31: 57-69.

Showler A T, Greenberg S M, Arnason J T (2004) Deterrent effects of four neem-based formulations on gravid female boll weevil (Coleoptera: Curculionidae) feeding and oviposition on cotton squares. J Econ Entomol 97: 414-421.

Silva F A C, Martinez S S (2004) Effect of neem seed oil aqueous solutions on survival and development of the predator Cycloneda sanguinea (L.) (Coleoptera: Coccinellidae). Neotrop Entomol 33: 751-757.

Souza J C, Reis PR (1997) Broca-do-café. Histórico, reconhecimento, biologia, prejuízos, moniotoramento e controle. Belo Horizonte, Epamig, Boletim Téc. 50, 40p.

Sponagel K W (1994) Eficacia del aceite de nim, extractos AZT y acetona de nim en el control de la broca del café Hypothenemus hampei en comparación con medidas químicas y biológicas. In Brechelt A, Hellpap C (eds) Memorias del 1er. Congreso Latinoamericano y del Caribe sobre Nim y otros Insecticidas Vegetales. Santo Domingo, GTZ, p.255-266.

Thacker J R M, Bryan W J, McGinley C, Heritage S, Strang R H $\mathrm{C}$ (2003) Field and laboratory studies on the effects of neem (Azadirachta indica) oil on the feeding activity of the large pine weevil (Hylobius abietis L.) and implications for pest control in commercial conifer plantations. Crop Prot 22: 753-760.

Vinuela E, Adan A, Gonzalez M, Budia F, Smagghe G, del Estal P (1998) Spinosad and azadirachtin: effects of two naturally derived pesticides against the predatory bug Podisus maculiventris (Say) (Hemiptera: Pentatomidae). Bol San Veg Plagas 24: 57-66.

Zevallos R F, Hömberg B F, Ripken R R (1996) Guía para la caficultura ecológica: café orgánico. Ed Novella Publigraf, Lima, 67p.

Received 28/V/09. Accepted 04/I/10. 